\title{
Bartter's syndrome type 5; a case report
}

\author{
Parsa Yousefichijan, Fatemeh Dorreh*, Masoud Rezagholi Zamenjany
}

Department of Pediatrics, Arak University of Medical Sciences, Arak, Iran

\section{A R T I C L E I N F O}

Article Type:

Case Report

\section{Article History:}

Received: 21 October 2016

Accepted: 29 December 2016

Published online: 16 January 2017

\section{Keywords:}

Bartter's syndrome

Calcium-sensing receptor

Metabolic alkalosis

\begin{abstract}
A B S T R A C T
Bartter's syndrome is a heterogeneous rare disease occurring due to deficiency in sodium and chloride absorption. Biochemical profile is hypokalemic metabolic alkalosis, renal salt wasting, elevated renin and aldosterone levels with normal or low blood pressure. In some individuals, hypercalciuria is also present. Mutations in several genes have been associated with the disorder. Gain of function mutations in the calcium-sensing receptor (CaSR) has been described in some patients with Bartter's syndrome associated to hypocalcemia and hypercalciuria (Bartter's syndrome type 5). In a 27-month-old boy with type 5 Bartter's syndrome, who presented with seizure, laboratory results showed hypocalcemia, metabolic alkalosis, sever hypokalemia and a low level of PTH. Calcium and vitamin D supplements were prescribed and the seizure was controlled. There are several subtypes of Bartter's syndrome with distinct phenotypes. Type 5 of Bartter's syndrome results from mutation leading to upregulation of the CaSR and therefore hypocalcemia and hypercalciuria in addition to the typical salt-losing phenotype.
\end{abstract}

Implication for health policy/practice/research/medical education:

Activating mutation of the calcium-sensing receptor (CaSR) causes hypocalcaemia with hypercalciuria and it may also cause a Bartter's phenotype by inhibition of transporters in thick ascending limb of the loop of Henle (Bartter's syndrome type 5). Several mutations have been identified in the CaSR gene. The clinical presentation and onset timing of Bartter phenotype differ according to the type of mutation.

Please cite this paper as: Yousefichijan P, Dorreh F. Rezagholi Zamenjany M. Bartter's syndrome type 5; a case report. J Renal Inj Prev. 2017;6(4):244-246. DOI: 10.15171/jrip.2017.46.

\section{Introduction}

Bartter's syndrome is a heterogeneous disorder characterized by deficient renal sodium and chloride reabsorption, and hypokalemic metabolic alkalosis with hyperreninemia, hyperaldosteronemia. Affected patients present with normal or low blood pressure, hyperreninemia, hypokalemia, and a tendency towards hypercalciuria and nephrocalcinosis in the neonatal variant $(1,2)$. Further abnormalities in the metabolism of calcium, calciotropic hormones, and inorganic phosphate have been noted, sometimes, in these disorders, although data characterizing the classic calciotropic hormone levels during stable phases of the condition are sparse (3).

Mutations in five genes that are expressed in the ascending limb have been identified in Bartter's syndrome, and the products of these genes either transport salt (three genes, types I-III ) or regulate salt transport ( types IV and V) (1).

Type 5 Bartter's syndrome has been recently defined as a Bartter's syndrome due to the most activating mutations of the calcium-sensing receptor (CaSR) and may manifest with variable severity (4).

CaSR is a G-protein coupled receptor essential for regulating secretion of parathyroid hormone. In addition to the parathyroid, CaSR is expressed in several other tissues, including the kidney. In fact, activating mutations of CaSR cause autosomal dominant hypocalcaemia associated with relative hypercalciuria (5).

We report a case with type 5 Bartter's syndrome, who presented with seizure and hypocalcemia.

\section{Case Report}

A 27-month-old boy was admitted to our hospital because of seizure and weakness and spasm in his extremities. A pediatric nephrologist had been following his since he was 6 months of age, with the diagnosis of typical Bartter's syndrome with hypokalemic metabolic alkalosis.

A history of maternal polyhydramnios with prematurity elicited and triangular facies presented on physical examination was noted. 
There was no family history of seizure or consanguinity. Ten days before he admitted with febrile convulsion.

At the time of admission, patient was treated with spironolactone $(2 \mathrm{mg} / \mathrm{kg} / \mathrm{d})$, potassium chloride $6 \%(6 \mathrm{mEq} /$ $\mathrm{kg} / \mathrm{d}$ ).

Physical examination on admission showed weight and height under the third percentile.

Consciousness, cranial nerves, respiratory muscles, and pain sensation were intact.

Analysis of arterial blood showed mild metabolic alkalosis ( $\mathrm{pH} 7.53, \mathrm{PaCO}_{2} 49 \mathrm{~mm} \mathrm{Hg}, \mathrm{PaO}_{2} 93 \mathrm{~mm} \mathrm{Hg}$, bicarbonate $37.3 \mathrm{mEq} / \mathrm{L})$. Serum electrolytes revealed severe hypokalemia $(2.1 \mathrm{mEq} / \mathrm{L})$, and serum sodium was $137 \mathrm{mEq} / \mathrm{L}$.

Initial serum biochemistry revealed the following; Calcium was $6.8 \mathrm{mg} / \mathrm{dL}$, phosphorus was $11.3 \mathrm{mg} / \mathrm{dL}$, alkaline phosphatase was $73 \mathrm{U} / \mathrm{L}$, magnesium levels was 3.1 $\mathrm{mg} / \mathrm{dL}$. Blood urea nitrogen and creatinine were normal. Complete blood count was normal. QTc was prolonged (0.52 seconds). Other laboratory data were a decreased level of parathyroid hormone $(\mathrm{PTH})$ concentration $(8.4$ $\rho g / m L)$ and $1,25(\mathrm{OH})_{2} \mathrm{D}_{3}(7.8 \mathrm{ng} / \mathrm{mL})$. Brain magnetic resonance imaging (MRI) was normal, however, electroencephalogram (EEG) was mildly abnormal.

Patient was treated with spironolactone, potassium chloride, gluconate calcium and calcitriol accordingly. Calcium level normalized after treatment and patient discharged with good condition.

\section{Discussion}

The association between severe hypocalcaemia and characteristics of Bartter's syndrome reported in this patient. In our case, the diagnosis of Bartter's syndrome was confirmed by a biochemical analysis suggestive of Bartter's syndrome. Hypocalcaemia with suppressed secretion of PTH and high fractional excretion of calcium suggested activating mutations of CaSR.

The extracellular CaSR plays an essential role in extracellular $\mathrm{Ca}^{2+}$ homeostasis by regulating the rate of PTH secretion and the rate of calcium reabsorption by the kidney. Renal CaSR activation is thought to inhibit cation reabsorption of paracellular divalent in the cortical ascending limb both directly and indirectly via a decrease in $\mathrm{NaCl}$ transport (6).

Bartter's syndrome type 5 has been described in association with four different heterozygous activating CaSR mutations (K29E, L125P, C131W and A843E). Of these, L125P, C131W and A843E were associated with classical features of Bartter's syndrome, including hypokalemic alkalosis and hyperreninemic hyperaldosteronism, and presented either in childhood or early adulthood. All affected patients had symptomatic hypocalcemia together with urinary calcium excretion elevations. In contrast, K29E was associated with a more limited phenotype characterized by mild hypokalemia and the absence of alkalosis (7). Vezzoli et al, reported two monozygotic twin sisters with autosomal dominant hypocalcemia $(\mathrm{ADH})$ due to a nonconservative activating CaSR mutation in the extracellular domain (K29E). They developed a Bartter's-like syndrome characterized by a mild phenotype (4). Our case had typical Bartter's syndrome and presented in infancy.

Molecular genetics studies are indicated to identify the primary genetic defect. A genetic study could not be performed in our case.

Patra et al reported a case of a 4-month-old infant with neonatal Bartter's syndrome, who presented only with status epilepticus. The patient had severe hyponatremia, which presented as seizures. However, the patient did not have any typical clinical manifestations like facial failure to thrive, dysmorphism or any polyuria history, vomiting or other suggestive features (8). Seizure in our case was due to hypocalcemia.

Chrispal et al, reviewed a patient with developed severe renal tubular dysfunction secondary to short-term amikacin therapy, resulting in refractory hypokalemia, hypocalcemia, hypomagnesemia, metabolic alkalosis and polyuria. This biochemical abnormalities constellation, mimic type $\mathrm{V}$ Bartter's syndrome, where there is activating mutation of the calcium sensing receptor in the distal tubule and thick ascending loop of Henle. In this case, amikacin was triggered this activation of the calcium sensing receptor. This phenomenon has been described with gentamicin though never with amikacin. Tubular dysfunction recovery, took 15 days following cessation of the offending drug, amikacin (9).

\section{Conclusion}

There are several subtypes of Bartter's syndrome with distinct phenotypes. Type 5 Bartter's syndrome results from mutation leading to upregulation of the CaSR and therefore hypocalcemia and hypercalciuria in addition to the typical salt-losing phenotype.

\section{Authors' contribution}

PY, MRZ and FD prepared the primary draft. FD and MR edited the paper. All authors read and signed the final paper.

\section{Conflicts of interest}

The authors declared no competing interests.

\section{Ethical considerations}

Ethical issues (including data fabrication, double publication, and plagiarism) have been completely observed by the authors. Informed consent was obtained from the patient for publication as a case report. This case report has also the ethical code of "IR.Arak.mu.Rec.1396.32" from the University.

\section{Funding/Support}

None.

\section{References}

1. Hebert SC. Bartter syndrome. Curr Opin Nephrol Hypertens. 2003;12:527-32.

2. Assadi F. Diagnosis of Hypokalemia A ProblemSolving Approach to Clinical Cases. Iran J Kidney Dis. 


\section{8;2:115-22.}

3. Bettinelli A, Viganò C, Provero MC, Barretta F, Albisetti A, Tedeschi S, et al. Phosphate homeostasis in Bartter syndrome: a case-control study. Pediatr Nephrol 2014; 29:2133-8.

4. Vezzoli G, Arcidiacono T, Paloschi V, Terranegra A, Biasion R, Weber G, et al. Autosomal dominant hypocalcemia with mild type 5 Bartter syndrome. J Nephrol. 2006;19:525-8.

5. Watanabe S, Fukumoto S, Chang H, Takeuchi Y, Hasegawa $\mathrm{Y}$, Okazaki R, et al. Association between activating mutations of calcium-sensing receptor and Bartter's syndrome. Lancet. 2002;360:692-4.

6. Vargas-Poussou R, Huang C, Hulin P, Houillier P, Jeunemaître X, Paillard M, Planelles G, et al. Functional characterization of a calcium-sensing receptor mutation in severe autosomal dominant hypocalcemia with a Bartterlike syndrome. J Am Soc Nephrol. 2002;13(9):2259-66.

7. Hannan FM, Thakker RV. Calcium-sensing receptor (CaSR) mutations and disorders of calcium, electrolyte and water metabolism. Best Pract Res Clin Endocrinol Metab. 2013;27:359-71. doi: 10.1016/j.beem.2013.04.007.

8. Patra S, Konar MC, Basu R, Khaowas AK, Dutta S, Sarkar D. Status epilepticus as the only presentation of the neonatal Bartter syndrome. Indian J Endocrinol Metab. 2012;16:3002. doi: 10.4103/2230-8210.93775.

9. Chrispal A, Boorugu H, Prabhakar AT, Moses V. Amikacin-induced type 5 Bartter-like syndrome with severe hypocalcemia. J Postgrad Med. 2009;55:208-10. doi: 10.4103/0022-3859.57407.

Copyright $\odot 2017$ The Author(s); Published by Nickan Research Institute. This is an open-access article distributed under the terms of the Creative Commons Attribution License (http://creativecommons.org/licenses/by/4.0), which permits unrestricted use, distribution, and reproduction in any medium, provided the original work is properly cited. 